\title{
Use of sanger and next-generation sequencing to screen for mosaic and intronic $A P C$ variants in unexplained colorectal polyposis patients
}

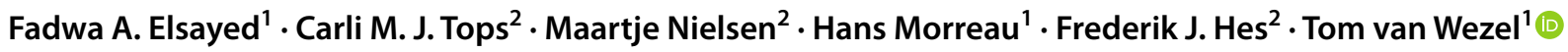

Received: 14 September 2020 / Accepted: 16 February 2021 / Published online: 8 March 2021

(c) The Author(s) 2021

\begin{abstract}
In addition to classic germline $A P C$ gene variants, $A P C$ mosaicism and deep intronic germline $A P C$ variants have also been reported to be causes of adenomatous polyposis. In this study, we investigated 80 unexplained colorectal polyposis patients without germline pathogenic variants in known polyposis predisposing genes to detect mosaic and deep intronic $A P C$ variants. All patients developed more than 50 colorectal polyps, with adenomas being predominantly observed. To detect $A P C$ mosaicism, we performed next-generation sequencing (NGS) in leukocyte DNA. Furthermore, using Sanger sequencing, the cohort was screened for the following previously reported deep intronic pathogenic germline APC variants: c. $1408+731 \mathrm{C}>\mathrm{T}$, p.(Gly471Serfs*55), c.1408+735A > T, p.(Gly471Serfs*55), c.1408+729A > G, p.(Gly471Serfs*55) and c.532-941G >A, p.(Phe178Argfs*22). We did not detect mosaic or intronic $A P C$ variants in the screened unexplained colorectal polyposis patients. The results of this study indicate that the deep intronic $A P C$ variants investigated in this study are not a cause of colorectal polyposis in this Dutch population. In addition, NGS did not detect any further mosaic variants in our cohort.
\end{abstract}

Keywords Unexplained colorectal polyposis $\cdot A P C \cdot$ Mosaic variants $\cdot$ Intronic variants $\cdot$ Pseudoexons

$\begin{array}{ll}\text { Abbreviations } \\ \text { FAP } & \text { Familial adenomatous polyposis syndrome } \\ \text { AFAP } & \text { Attenuated FAP } \\ \text { NGS } & \text { Next-generation sequencing } \\ \text { DGGE } & \text { Denaturing gradient gel electrophoresis } \\ \text { PTT } & \text { Protein truncation test } \\ \text { HRMA } & \text { High resolution melting analysis } \\ \text { IGV } & \text { Integrative genomics viewer } \\ \text { VAF } & \text { Variant allele frequency }\end{array}$

\section{Introduction}

Pathogenic germline variants in APC (MIM\# 611,731) cause familial adenomatous polyposis syndrome (FAP; MIM\# $175,100)$, a rare autosomal dominant-inherited syndrome characterized by the development of multiple colorectal adenomas and a very high risk of colorectal cancer [1-4].

Tom van Wezel

T.van_Wezel@lumc.nl

1 Department of Pathology, Leiden University Medical Center, Leiden, the Netherlands

2 Department of Clinical Genetics, Leiden University Medical Center, Leiden, the Netherlands
In classic FAP, patients develop hundreds to thousands of colorectal adenomatous polyps, while in attenuated FAP (AFAP), patients develop fewer adenomas $(<100)$ at a later age than those with classical FAP [5-8]. A subset of patients with multiple colorectal adenomas and no $A P C$ germline variants have been found to carry biallelic variants in the base excision repair gene MUTYH (MIM\# 604,933), causing MUTYH-associated polyposis (MAP; MIM\# 608,456) [9]. In addition, a number of other genes associated with adenomatous polyposis, such as POLE, POLD1, NTHL1, MSH3 and $M L H 3$, have recently been reported [10-13]. The detection rate of $A P C$ variants in FAP patients depends on phenotype and methods. In classic FAP, APC germline variants can be detected in up to $85 \%$ of patients $[14,15]$; however, the detection rates of $A P C$ germline variants in patients with fewer colorectal adenomatous polyps (AFAP patients) are lower, ranging from 10 to $30 \%$ of patients [14, 16], suggesting that a proportion of pathogenic variants remain undetected by routine methods [17-19]. Mosaic APC variants and deep intronic variants localized in regions not covered by PCR-based diagnostics were previously identified as additional causal factors. Using RNA-based assays and next-generation sequencing (NGS), it has been shown that a proportion of variant-negative FAP patients harbor molecular changes in deep intronic regions of $A P C[19,20]$. These 
studies identified deep intronic $A P C$ variants that result in pseudoexon formation $[19,20]$. Through the use of sensitive techniques, somatic $A P C$ mosaicism has been demonstrated in a minority of adenomatous polyposis patients [21-26]. In addition, using deep sequence analysis of $A P C$ in DNA isolated from multiple adenomas, mosaic variants were identified in 9 of 18 patients with 21 to 100 adenomas; in some of these cases, NGS also detected the variants in leukocyte DNA at low frequency [27]. In this study, we investigate the role of deep intronic germline $A P C$ variants and mosaic $A P C$ variants in leukocyte DNA as possible genetic causes of colorectal polyposis in a Dutch cohort of unexplained patients with more than 50 polyps.

\section{Materials and methods}

\section{Patients}

A total of 80 index patients with more than 50 colorectal polyps (Table 1) were selected from a previously described cohort [28-31]. The cohort included patients previously screened for germline mosaic $A P C$ variants by denaturing gradient gel electrophoresis (DGGE) [17], the protein truncation test (PTT) [17] and high resolution melting analysis (HRMA) [21]. All cases tested negative for pathogenic germline variants in $A P C, M U T Y H, P O L E$, and POLDI and for NTHL1 hotspot variants. Clinicopathological data included date of birth, gender, age at diagnosis of colorectal polyps/ adenomas, cumulative number of polyps, location and histology of polyps/adenomas, information on CRC and presence of polyps/CRC in first-degree family members. Since the term serrated adenomas is currently preferred over hyperplastic polyps, we lumped together polyps described as such under the term sessile serrated lesions with or without dysplasia. Three controls were included in this study. Leukocyte DNA from this cohort was available for the study. The study was approved by the medical ethics committee of Leiden University Medical Center, protocol P01-019.

\section{$A P C$ intronic variant screening}

Leukocyte DNA of the patients was screened for the intronic $A P C$ variants in Table 2 using Sanger sequencing. Primers were designed using Primer3 software http://primer3.ut. ee/ and were obtained from Eurofins Genomics (Ebersberg, Germany). The following primers with universal M13 tails were used: c. $1408+731 \mathrm{C}>\mathrm{T}$, c. $1408+735 \mathrm{~A}>\mathrm{T}$ and c. $1408+729 \mathrm{~A}>\mathrm{G}$; forward: 5'-TGTAAAACGACGGCC AGTATCATGCTGAACCATCTCAT-3' and reverse: 5' CAGGAAACAGCTATGACCAAATGACGAATGAAA CGATG-3'. For c.532-941G > A; forward: 5' TGTAAA ACGACGGCCAGTAGAGGGTTTGGGAAGTGGAG-3'
Table 1 Clinical characteristics of the colorectal polyposis patients $(\mathrm{n}=80)$

\begin{tabular}{ll}
\hline Patient characteristics & Individuals $\%$ \\
\hline Number of polyps & \\
$>100$ & $29(36.2 \%)$ \\
$50-100$ & $51(63.8 \%)$ \\
Type of polyps & \\
Adenomas & $36(45 \%)$ \\
Mixed (Adenomas +Serrated $\left.{ }^{*}\right)$ & $38(47.5 \%)$ \\
Serrated & $5(6.2 \%)$ \\
Unknown & $1(1.3 \%)$ \\
Age at diagnosis with polyposis & \\
$\geq 50$ years & $49(61.3 \%)$ \\
$<50$ years & $31(38.7 \%)$ \\
Diagnosed with CRC & \\
Yes & $27(33.8 \%)$ \\
No & $53(66.2 \%)$ \\
Age at diagnosis with CRC & \\
$>50$ & $19(70.4 \%)$ \\
$\leq 48$ & $8(29.6 \%)$ \\
Sex & \\
Male & $53(66.2 \%)$ \\
Female & $27(33.8 \%)$ \\
Polyposis family & \\
Polyposis family & 29 \\
Unknown polyposis family & 37 \\
CRC family & 14 \\
No CRC family family & 33 \\
Unknown & 13 \\
\hline & \\
\hline &
\end{tabular}

*Sessile serrated lesions with or without dysplasia

and reverse: 5' CAGGAAACAGCTATGACCTCTGTGTGC CCTTAGAAAACTG-3'. Sanger sequencing of the PCR amplified fragments was performed by Macrogen (Amsterdam, Netherlands). The sequencing results were analyzed using Mutation Surveyor software (Sofgenetics, State College PA, USA).

\section{Next-generation sequencing and data analysis}

Deep $A P C$ sequencing was performed using a previously described custom $A P C$ panel [27]. The complete sequencing panel consisted of 115 amplicons $(11,216 \mathrm{bp})$, covering 99.3\% of the coding regions of $A P C$. Libraries were prepared with Ion Ampliseq ${ }^{\mathrm{TM}} 2.0$ Kit (Thermo Fisher Scientific, Bleiswijk, The Netherlands) according to the manufacturer's instructions and were sequenced on the Ion Torrent Proton Platform (Thermo Fisher Scientific, Bleiswijk, The Netherlands). Sequence data were analyzed as described 
Table 2 Summary of the germline pathogenic $A P C$ intronic variants

\begin{tabular}{llllll}
\hline Intron & Alteration in genomic DNA & Insertion length (bp) & RNA alteration & Predicted protein alteration & Publication \\
\hline 4 & c.532-941G $>$ A & Insertion of $167 \mathrm{bp}$ & r.531_532ins532-1106_532-940 & p.Phe178Argfs*22 & [19] \\
10 & c.1408+731C $>$ T & Insertion of 83 bp & r.1408_1409ins1408+647_1408+729 & p.Gly471Serfs*55 \\
10 & c.1408+735A $>$ T & Insertion of 83 bp & r.1408_1409ins1408+647_1408+729 & p.Gly471Serfs*55 & [19, 20] \\
10 & c. $1408+729 \mathrm{~A}>\mathrm{G}$ & Insertion of 83 bp & r.1408_1409ins1408+647_1408+729 & p.Gly471Serfs*55 & [20] \\
\hline
\end{tabular}

previously [27]. Variants were annotated to the GenBank reference sequence NM_000038.4. The Integrative Genomics Viewer (IGV) (https://www.broadinstitute.org/igv/) was used to visualize the read alignment and the presence of variants against the reference genome.

\section{Results and discussion}

In this study, we attempt to identify the genetic causes of colorectal polyposis in unexplained patients with colorectal polyposis. Deep NGS of APC was performed to identify possible undetected pathogenic mosaic variants. Furthermore, $A P C$ intronic germline variants described previously [19, 20] were studied to evaluate their role. A high-risk cohort was selected for this study, consisting of 80 index patients with $\geq 50$ colorectal polyps (Table 1 ), of whom many had a relatively early onset, which increases the probability of finding undiscovered mosaic or intronic variants. The mean age at diagnosis of colorectal polyps was 49 years (range $12-80)$. The majority of patients $(n=51,63.8 \%$ with a mean age of 51 years at diagnosis) had a cumulative polyp count between 50 and 100 , while 29 patients $(36.2 \%$ with a mean age of 46 years at diagnosis) showed more than 100 polyps. Forty-five percent of the patients displayed only adenomatous polyps, while $47.5 \%$ of the patients displayed a mixed phenotype with adenomas and sessile serrated lesions with or without dysplasia. CRC was found in 27 patients $(33.8 \%$, with a mean age of 56 years, range 37-80). The clinical characteristics of the patients are summarized in Table 1.

First, we screened the leukocyte DNA of 80 patients for the following deep intronic heterozygous germline variants in $A P C$ : c. $1408+731 \mathrm{C}>\mathrm{T}$, p. $($ Gly471Serfs*55), c. $1408+735 \mathrm{~A}>\mathrm{T}, \quad$ p. $(\mathrm{G} 1 \mathrm{y} 471 \mathrm{Serfs} * 55)$, c. $1408+729 \mathrm{~A}>\mathrm{G}$, p. $($ Gly471Serfs*55) and c.532941G > A, p.(Phe178Argfs*22). We did not detect any of these variants in our cohort. The study by Spier et al. [19] was the first to describe $A P C$-related pseudoexons in FAP patients from Germany. These pseudoexons were caused by three heterozygous germline variants with a combined frequency of $6.4 \%(8 / 125)$; $A P C$ c.532-941G $>$ A was identified in five patients, $A P C$ c. $1408+731 \mathrm{C}>\mathrm{T}$ was identified in two patients, and $A P C$ c. $1408+735 \mathrm{~A}>\mathrm{T}$ was identified in one patient [19]. In a second study by
Nieminen et al. [20], two additional intronic variants were identified in a cohort of 54 patients from Finland: $A P C$ c. $1408+729 \mathrm{~A}>\mathrm{G}$ and $A P C$ c.646-1806 $\mathrm{T}>\mathrm{G}$ and the variant identified previously by Spier et al., $A P C$ c. $1408+731 \mathrm{C}>\mathrm{T}$. The overall reported frequency of these variants from the study by Nieminen et al. was $5.5 \%$ (3/54). The reported frequency of these intronic variants from both studies is approximately $6 \%$. Nevertheless, we could not detect these variants in our cohort, possibly because either the frequency of intronic variants is lower in the Dutch population and the sample size of our cohort is not large enough or because these variants are local founder variants.

Subsequently, we performed deep $A P C$ sequencing of leukocyte DNA from 80 colorectal polyposis patients. Our positive controls were two previously described cases with mosaic $A P C$ variants [27]; $A P C$ c.4110_4111delAA was reported to be present in leukocyte DNA with $4 \%$ variant allele frequency (VAF), and APC c.2493dupA was reported with a VAF of $3 \%$ in leukocyte DNA. The $A P C$ mosaic variant c. $4057 \mathrm{G}>\mathrm{T}$ served as a negative control, as the variant was detected previously [27] in normal colonic mucosa and was absent in leukocyte DNA. Both positive controls, APC c.4110_4111delAA (Fig. 1) and APC c.2493dupA, were clearly present, while $A P C$ c $.4057 \mathrm{G}>\mathrm{T}$ was absent in the negative control. No additional $A P C$ mosaic variants were detected in our cohort. A limitation of this study is that we used only leukocyte DNA for mosaicism screening due to the scarcity of available DNA from patient adenomas. Mosaicism might remain undetectable or be overlooked if the molecular analysis is limited to blood, even when sensitive techniques are applied, due to very low or even absent presentation of the mutated allele [23, 27]. Peripheral blood cells arise from the mesoderm, and when the variant occurs after mesoderm and endoderm specification (early postzygotic mutation), the mosaicism is likely restricted to the colon and is difficult to detect the variant in leukocyte DNA [23, 27, 32, 33]. In a previous study, it was recommended to test at least two or more adenomas to detect mosaic variants [27].

A recent systematic review of current $A P C$ mosaicism studies recommends testing adenomas from the polyposis patients without $A P C$ germline variant to allow the detection of low allele frequency mosaicism as well as mosaicism 


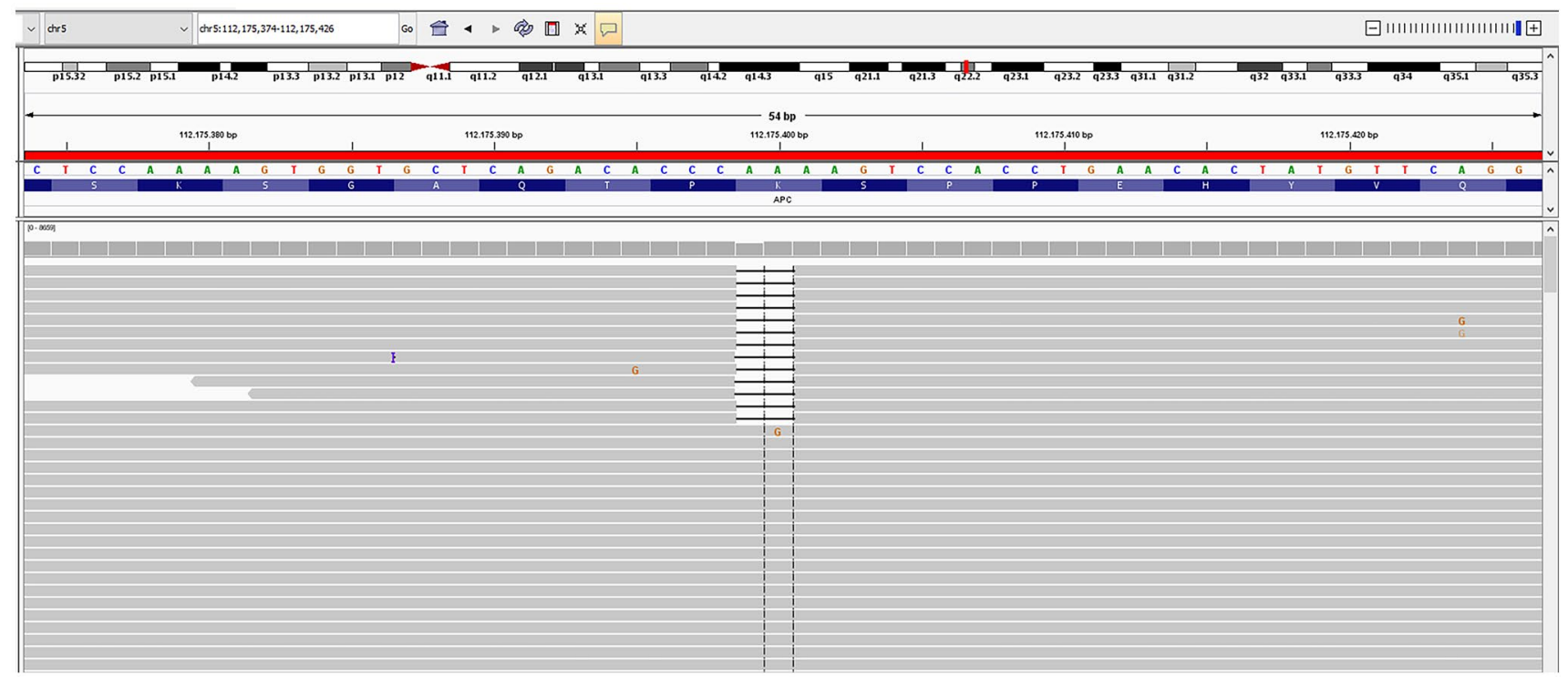

Fig. 1 Integrative Genomics Viewer (IGV) images of next-generation sequencing (NGS) data of mosaic APC c.4110_4111delAA variant detected in the leukocyte DNA of the positive control sample

confined to colon [33]. Consequently, in our study, $A P C$ mosaic variants confined to the colon could have been missed because we could not screen the DNA from the adenomas of the patients.

In conclusion, we did not detect any of the four previously reported $A P C$ intronic variants in our cohort. We also did not detect mosaic $A P C$ variants in our cohort using deep sequencing analysis in blood. This finding suggests that the benefit of using targeted amplicon-based NGS to further scrutinize the $A P C$ gene in unexplained cases of polyposis is limited. Analyzing DNA from adenomas in addition to leukocyte DNA is recommended to detect a possible underlying mosaicism. Also, other approaches, such as whole genome sequencing or transcriptome sequencing, could be employed to detect undiscovered intronic or promoter variants or other regulatory variants.

Acknowledgements The authors would like to thank Demi van Egmond for technical support and Diantha Terlouw for support with clinical data.

Funding Grant support: This study was supported in part by the Dutch Digestive Foundation (MLDS FP13-13 to TVW).

\section{Compliance with ethical standards}

Conflict of interest The authors have no conflict of interest to declare.

Open Access This article is licensed under a Creative Commons Attribution 4.0 International License, which permits use, sharing, adaptation, distribution and reproduction in any medium or format, as long as you give appropriate credit to the original author(s) and the source, provide a link to the Creative Commons licence, and indicate if changes were made. The images or other third party material in this article are included in the article's Creative Commons licence, unless indicated otherwise in a credit line to the material. If material is not included in the article's Creative Commons licence and your intended use is not permitted by statutory regulation or exceeds the permitted use, you will need to obtain permission directly from the copyright holder. To view a copy of this licence, visit http://creativecommons.org/licenses/by/4.0/.

\section{References}

1. Bodmer WF, Bailey CJ, Bodmer J et al (1987) Localization of the gene for familial adenomatous polyposis on chromosome 5 . Nature 328(6131):614-616. https://doi.org/10.1038/328614a0

2. Bisgaard ML, Fenger K, Bulow S, Niebuhr E, Mohr J (1994) Familial adenomatous polyposis (FAP): frequency, penetrance, and mutation rate. Hum Mutat 3(2):121-125. https://doi. org/10.1002/humu.1380030206

3. Fearnhead NS, Britton MP, Bodmer WF (2001) The ABC of APC. Hum Mol Genet 10(7):721-733. https://doi.org/10.1093/ hmg/10.7.721

4. Yurgelun MB, Kulke MH, Fuchs CS et al (2017) Cancer susceptibility gene mutations in individuals with colorectal cancer. J Clin Oncol: Off J Am Soc Clin Oncol 35(10):1086-1095. https://doi. org/10.1200/jco.2016.71.0012

5. Knudsen AL, Bisgaard ML, Bulow S (2003) Attenuated familial adenomatous polyposis (AFAP) A review of the literature. Familial Cancer 2(1):43-55. https://doi.org/10.1023/a:1023286520725

6. Jasperson KW, Tuohy TM, Neklason DW, Burt RW (2010) Hereditary and familial colon cancer. Gastroenterology 138(6):20442058. https://doi.org/10.1053/j.gastro.2010.01.054

7. Nielsen M, Hes FJ, Nagengast FM et al (2007) Germline mutations in APC and MUTYH are responsible for the majority of families with attenuated familial adenomatous polyposis. Clin Genet 71(5):427-433. https://doi.org/10.1111/j.1399-0004.2007.00766 $\mathrm{x}$ 
8. Nieuwenhuis MH, Vasen HF (2007) Correlations between mutation site in APC and phenotype of familial adenomatous polyposis (FAP): a review of the literature. Crit Rev Oncol Hematol 61(2):153-161. https://doi.org/10.1016/j.critrevonc.2006.07.004

9. Al-Tassan N, Chmiel NH, Maynard J et al (2002) Inherited variants of $\mathrm{MYH}$ associated with somatic $\mathrm{G}: \mathrm{C}->\mathrm{T}$ : a mutations in colorectal tumors. Nat Genet 30(2):227-232. https://doi. org/10.1038/ng828

10. Palles C, Cazier JB, Howarth KM et al (2013) Germline mutations affecting the proofreading domains of POLE and POLD1 predispose to colorectal adenomas and carcinomas. Nat Genet 45(2):136-144. https://doi.org/10.1038/ng.2503

11. Weren RD, Ligtenberg MJ, Kets CM et al (2015) A germline homozygous mutation in the base-excision repair gene NTHL1 causes adenomatous polyposis and colorectal cancer. Nat Genet 47(6):668-671. https://doi.org/10.1038/ng.3287

12. Adam R, Spier I, Zhao B et al (2016) Exome sequencing identifies biallelic MSH3 germline mutations as a recessive subtype of colorectal adenomatous polyposis. Am J Hum Genet 99(2):337-351. https://doi.org/10.1016/j.ajhg.2016.06.015

13. Olkinuora A, Nieminen TT, Mårtensson E et al (2019) Biallelic germline nonsense variant of MLH3 underlies polyposis predisposition. Genet Med: Off J Am College Med Genet 21(8):18681873. https://doi.org/10.1038/s41436-018-0405-x

14. Friedl W, Aretz S (2005) Familial adenomatous polyposis: experience from a study of 1164 unrelated german polyposis patients. Hereditary Cancer Clin Pract 3(3):95-114. https://doi. org/10.1186/1897-4287-3-3-95

15. Aretz S, Stienen D, Uhlhaas S et al (2005) Large submicroscopic genomic APC deletions are a common cause of typical familial adenomatous polyposis. J Med Genet 42(2):185-192. https://doi. org/10.1136/jmg.2004.022822

16. Terlouw D, Suerink M, Singh SS et al (2020) Declining detection rates for APC and biallelic MUTYH variants in polyposis patients, implications for DNA testing policy. Eur J Human Genet: EJHG 28(2):222-230. https://doi.org/10.1038/s41431-019-0509-z

17. Hes FJ, Nielsen M, Bik EC et al (2008) Somatic APC mosaicism: an underestimated cause of polyposis coli. Gut 57(1):71-76. https ://doi.org/10.1136/gut.2006.117796

18. Rohlin A, Wernersson J, Engwall Y, Wiklund L, Bjork J, Nordling M (2009) Parallel sequencing used in detection of mosaic mutations: comparison with four diagnostic DNA screening techniques. Hum Mutat 30(6):1012-1020. https://doi.org/10.1002/ humu. 20980

19. Spier I, Horpaopan S, Vogt $S$ et al (2012) Deep intronic APC mutations explain a substantial proportion of patients with familial or early-onset adenomatous polyposis. Hum Mutat 33(7):10451050. https://doi.org/10.1002/humu.22082

20. Nieminen TT, Pavicic W, Porkka N et al (2016) Pseudoexons provide a mechanism for allele-specific expression of APC in familial adenomatous polyposis. Oncotarget 7(43):70685-70698. https:// doi.org/10.18632/oncotarget.12206

21. Out AA, van Minderhout IJ, van der Stoep N et al (2015) Highresolution melting (HRM) re-analysis of a polyposis patients cohort reveals previously undetected heterozygous and mosaic APC gene mutations. Fam Cancer 14(2):247-257. https://doi. org/10.1007/s10689-015-9780-5
22. Yamaguchi K, Komura M, Yamaguchi R et al (2015) Detection of APC mosaicism by next-generation sequencing in an FAP patient. J Hum Genet 60(5):227-231. https://doi.org/10.1038/jhg.2015.14

23. Spier I, Drichel D, Kerick M et al (2016) Low-level APC mutational mosaicism is the underlying cause in a substantial fraction of unexplained colorectal adenomatous polyposis cases. J Med Genet 53(3):172-179. https://doi.org/10.1136/jmedgenet-2015103468

24. Ciavarella M, Miccoli S, Prossomariti A et al (2018) Somatic APC mosaicism and oligogenic inheritance in genetically unsolved colorectal adenomatous polyposis patients. Eur J Human Genet: EJHG 26(3):387-395. https://doi.org/10.1038/s41431-017-0086-y

25. Kim B, Won D, Jang M et al (2019) Next-generation sequencing with comprehensive bioinformatics analysis facilitates somatic mosaic APC gene mutation detection in patients with familial adenomatous polyposis. BMC Med Genom 12(1):103. https://doi. org/10.1186/s12920-019-0553-0

26. Urbanova M, Hirschfeldova K, Obeidova L et al (2019) Two Czech patients with familial adenomatous polyposis presenting mosaicism in APC gene. Neoplasma 66(2):294-300. https://doi. org/10.4149/neo_2018_180731N559

27. Jansen AM, Crobach S, Geurts-Giele WR et al (2017) Distinct patterns of somatic mosaicism in the APC gene in neoplasms from patients with unexplained adenomatous polyposis. Gastroenterology 152(3):546-9.e3. https://doi.org/10.1053/j.gastro.2016.10.040

28. Hes FJ, Ruano D, Nieuwenhuis M et al (2014) Colorectal cancer risk variants on 11q23 and 15q13 are associated with unexplained adenomatous polyposis. J Med Genet 51(1):55-60. https://doi. org/10.1136/jmedgenet-2013-102000

29. Elsayed FA, Kets CM, Ruano D et al (2015) Germline variants in POLE are associated with early onset mismatch repair deficient colorectal cancer. Eur J Human Genet: EJHG 23(8):1080-1084. https://doi.org/10.1038/ejhg.2014.242

30. Elsayed FA, Tops CMJ, Nielsen M, et al. (2019) Low frequency of POLD1 and POLE exonuclease domain variants in patients with multiple colorectal polyps. Molecular genetics \& genomic medicine: e603 https://doi.org/https://doi.org/10.1002/mgg3.603

31. Grolleman JE, de Voer RM, Elsayed FA et al (2019) Mutational Signature Analysis Reveals NTHL1 Deficiency to Cause a Multitumor Phenotype. Cancer Cell 35(2):256-66.e5. https://doi. org/10.1016/j.ccell.2018.12.011

32. Tuohy TM, Burt RW (2008) Somatic mosaicism: a cause for unexplained cases of FAP? Gut 57(1):10-12. https://doi.org/10.1136/ gut.2007.133108

33. Jansen AML, Goel A (2020) Mosaicism in patients with colorectal cancer or polyposis syndromes: a systematic review. Clin Gastroenterol Hepatol: Off Clin Pract J Am Gastroenterol Assoc 18(9):1949-1960. https://doi.org/10.1016/j.cgh.2020.02.049

Publisher's Note Springer Nature remains neutral with regard to jurisdictional claims in published maps and institutional affiliations. 